all cases was due to the original disease during which the thrombosis had ensued.

Secondary Thrombosis.-This occurred 36 times. Of these 22 were due to ear disease, and the infection had spread from the posterior wall of the petrous bone in nine, the dura mater being inflamed, sloughing, or suppurating. In 4 the clotting spread to the longitudinal sinus, and in 11 to the jugular vein. Three-quarters of the patients died with pulmonary pyæmia, which the breaking down thrombus had set up. Fourteen cases remain for consideration. Seven of the cases were traumatic, once the bone was exposed and inflamed, in six there was a fracture, three times it was compound, and in four it ran across the sinus. The sinus was lacerated twice. Of the remaining seven, three had spread from malignant pustules or carbuncles on the face, two from an adjacent pachymeningitis, one from compression by a growth, and only one from a distant source, namely, from pyæmia set up by a carbuncle on the back. The clot was found in the longitudinal sinus in three, in the lateral in nine, and in the cavernous in three [spreading from the facial and ophthalmic veins]. Once the clot had extended into the circular and into the inferior petrosal sinuses, and only once into a cerebral vein. The patients were all males; ten of them were between the ages of 30 and 60 , the youngest (boys) were 7 and 9. Three times meningitis was set up, and six times pyæmic abscesses in the lung. The condition of the clot varied greatly ; in eight cases it was suppurating, in four comparatively recent, and in the two associated with pachymeningitis it was firm and well organised.

In the majority of the cases the symptoms were mainly those of pyæmia, associated in some with physical signs of disease in the lung. In two cases in which the fracture ran across the groove for the lateral sinus, extreme difficulty in respiration came on at the end of two weeks, and rapidly proved fatal. Thrombosis had taken place in the outer part of the sinus, and had spread downwards to the foramen lacerum jugular. Probably the consequent distension at this spot had led to pressure on the vagus, and thus to the urgent respiratory symptoms. The cases of pachymeningitis had, the one, intense headaches worse during the last three months of life ending in coms; and the other, epileptiform convulsions; but it is not possible to determine to what extent these symptoms were due to the thrombosis. In two instances the optic discs were noted to be swollen.

The cases which could have possibly have been diagnosed during life, were those in which the clotting had spread from inflammation on the face, and from the ear, and some of those stcondary to fractures of the base of the skull; but in more than half of the total series this was not possible.

Forty-four Cases of Thrombosis of the Sinuses. Primary. Secondary.

\begin{tabular}{llrlrrrrr} 
& & \multicolumn{9}{c}{ Ear Disease. } & \multicolumn{3}{c}{ Other Causes. } & Total. \\
Longitudinal Sinus & $\ldots$ & 5 & $\ldots$ & \multicolumn{1}{c}{} & $\ldots$ & 3 & $\ldots$ & 12 \\
Lateral sinus $\ldots$ & $\ldots$ & 5 & $\ldots$ & $2 \cdot$ & $\ldots$ & 9 & $\ldots$ & 36 \\
Cerebral veins $\ldots$ & $\ldots$ & 5 & $\ldots$ & 1 & $\ldots$ & 1 & $\ldots$ & -7 \\
Cavernous sinus & $\ldots$ & - & $\ldots$ & 1 & $\ldots$ & 3 & $\ldots$ & 4 \\
Circular $\quad \ldots$ & $\ldots$ & - & $\ldots$ & 1 & $\ldots$ & 1 & $\ldots$ & 2 \\
Inferior petrosal & $\ldots$ & - & $\ldots$ & 1 & $\ldots$ & 1 & $\ldots$ & 2 \\
Superior petrosal & $\ldots$ & - & $\ldots$ & 2 & $\ldots$ & - & $\ldots$ & 2
\end{tabular}

SocIETy FOR THE STUDY OF INEBRIETY.-At the annual meeting on Tuesday last in the rooms of the Medical Society of London, after a reception to Dr. F. R. Lees, the President (Dr. Norman Kerr), in his annual address, referred to the marked advance in public opinion on compulsory legislation for diseased inebriates, as evidenced by the fact that the Inebriates' Legislation"Committee of the British Medical Association had, in response to circulars to Poor-law guardians, received five times more replies in 1889 than in 1882 . The favourable returns were in much the same proportion. Scotland, through the legal, clerical, and medical professions, was asking for full power to compel inebriates of all classes to enter special homes, and for the treatment of the poor at the public charge. The records of the Dalrymple Home for gentlemen at Rickmansworth proved that scientific treatment of the disease of inebriety was very successful, more than one-half of the patients discharged having kept firm. The demand for compulsion was also growing on the Continent. A strong protest was made against the employment of hypnotism in the treatment of inebriety.

\author{
A CASE OF \\ LOCALISATION OF A LIMITED LESION \\ OF THE SPINAL CORD, \\ FROM PHYSIOLOGICAL DATA. \\ Bx W ILLIAM MACEWEN, M.D., \\ Surgeon, Royal Infirmary, Glasgow.
}

THE following case is interesting from a physiological aspect, especially regarding the function of the anterior or direct tracts of the cord. It is therefore given in extenso.

H. R., aged 60, labourer, was admitted to Ward 29, Royal Infirmary, Glasgow, October 31st, 1889, suffering from an injury to the cervical region of the spinal cord.

He had fallen a distance of fifteen feet from a hayrick. $\mathrm{He}$ cannot describe the exact position he was in when he fell, and no one saw him fall, but the bystanders found him on the ground with his face downwards, and they considered him unconscious. He considered that he was unconscious for about half a minute, and afterwards he found himself lying on his face quite unable to move. When admitted, he complained of pain in the neck in the region of the fourth, fifth, and sixth cervical vertebræ, and Dr. Johnston (house-surgeon) believed he detected something like osseous crepitation, such as might be occasioned by separation of one of the cervical spines.

On admission, the patient, who was quite conscious, lay on his back with both arms abducted to nearly a right angle, the forearms fully flexed on the arms, and the hands lying on the chest. The wrist was flexed, as were the fingers, with the exception of the index, which was partially extended. The little finger was most flexed, the others less so. The right index finger, though extended, was found to be ankylosed in that position, but the left was normal in this respect. He had absolutely no grasp. $\mathrm{He}$ could not extend his arms, but when passively extended he could fully flex the forearm by the biceps and brachialis anticus. Occasionally this flexion was involuntary. He could raise his upper arm easily by the shoulder muscles namely, deltoid, trapezius, supraspinatus, but beside that there was a distinct adduction in his attempts to raise the arms which seemed to be occasioned by the coraco-brachialis and possibly the pectorals.

The muscles of the shoulder-joint were in very good form. The supra- and infra-spinati, the deltoid, biceps, and brachialis anticus contracting when he wished to raise the arm, though all were feeble in their action. He could not supinate his forearm. Several of the muscles in the upper arm, but especially the biceps, contracted on touch, and the latter also contracted automatically when the forearm was extended.

The breathing was distinctly diaphragmatic. The chest was extended and fixed, and the intercostal muscles were inactive. The ribs were fixed, and the intercostal tissues were blown out and sucked in on each expiration and inspiration, very much like pieces of inert membrane. In the lower limbs the power was good, as tested while the patient lay in bed. He could lift his legs right up from the bed, and flex and extend them with ease.

Sensations.-The sensation of the arms was slightly dulled, and in the forearm and hand the dulness was increased from the outer toward the inner side, and on the ulnar border of the right it was entirely wanting, while the sensation was present to a slight ex tent in the left.

The cutaneous reflexes were much impaired, with the exception of the plantar, which was normal. The cremasteric reflex was absent, as were likewise the patellar reflex and ankle clonus. The bladder emptied itself when full, but the urine did not dribble away. He knew when the urine was flowing, but could not restrain it. The motions were also passed in bed.

Eyes.-The palpebral clefts were narrow. The pupils were in a state of stabile myosis. There was paralysis to light and skin reflexes, but there was slight contraction to accommodation. On dilatation of the pupils by homatropine, the fundifwere normal, possibly a little congested. 
There were fibrillar twitchings all over the body, especially in the lege.

For the first twelve days, and especially during the last of them, there were considerable changes, which slowly occurred. First, the power of the shoulder muscles became greatly impaired, especially on the right side, so that he could not raise his right arm, and the power of doing so on the left was greatly lessened. The mussles of the upper arms had become rigid, markedly so on the right. The movements of the left leg were impaired, and were not under perfect control. Meantime he complained of great pain in the arms, especially in the elbows. This pain was not present at first when the arms were not touched, though he complained of a "stiffness" and uneasy sensation when they were forcibly extended.

There was no observed vasomotor disturbance, no unilateral flushings or sweatings. The temperature up to November 14th was about normal $\left(98^{\circ}\right.$ to $\left.98.6^{\circ}\right)$. From November 14 th the rectal temperature has been subnormal, running down to $95.6^{\circ}$, and on two occasions, on November 27th and 28th, the mercury would not rise to the level of the register, which commences at $95^{\circ}$. These latter observations were several times repeated, and with three thermometers to prevent mistakes. Several times this depression of temperature continued for at least some hours. From November 11th to 14th the temperature was taken every two hours in both ears. Although there was a difference of a few points, never reaching to a degree, it was not always lower on one side than the other. On the first day it was a little higher on the right side than the left ; during the subsequent days it was a little lower on the right side than the left.

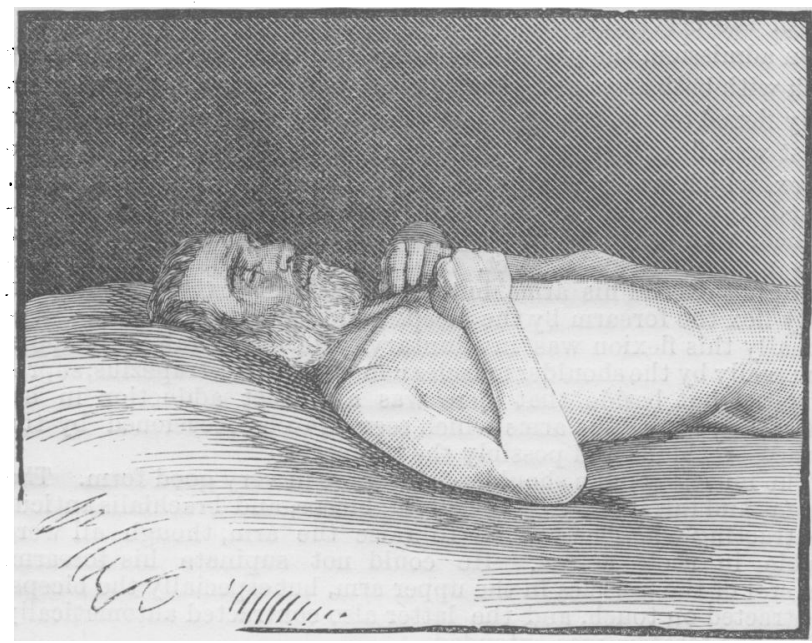

December 13th, 1889. Since last note there has been a gradual improvement. The deficiency of power in the left leg lasted only a few days, and the power of the lower limbs, as far as they can be tested in bed, is good. The power of the upper arms is still very deficient, but is not so limited as it was. He begins to move the fingers of both hande. His temperature has slightly improved, and the intercostals now take part in breathing, which is both thoracic and abdominal (massage and electricity have been used to the upper arms).

Eyes.-Nothing abnormal was detected in either fundus, except a posterior staphyloma.

State on Dismissal January 18th, 1890.-The patient left the infirmary on January 18th, 1890 , seventy-nine days after admission. About the eighth week he was able to rise out of bed, and for three weeks before leaving he was able to walk round the ward. His left hand and arm he could raise to the back of his head. His grasp was fair, but his elbow could not be extended beyond a right angle, owing to the rigidity of the biceps and the flexor muscles. With his right arm, which was also flexed at a right angle, he had much less movement than in the left. His grasp was almost absent in the right. He could oppose his thumb very slightly, and move his distal phalanges slightly. The only movement in the rest of the arm was diminished adduction and abduction of the elbow.
There was considerable atrophy of some of the muscles of the arms; those most affected were the extensors of the forearm and hand with the interossei.

The breathing was both thoracic and abdominal; there was no rigidity or contraction about the neck. His appetite was excellent, and he was increasing in weight.

Some weeks before leaving his bladder and rectum were restored in function.

REMARKS. -This is a case of limited lesion of the cervicat region of the cord concentrated at the lower part of the cervical enlargement. The diaphragmatic breathing, which was vigorous and well sustained throughout, while the action of the intercostals was in abeyance, showed that the lesion was under the fourth cervical and above the second dorsal.

The group of muscles involved in Erb's paralysis of the upper arm were here affected with paresis. These were the supra- and infra-spinati, the deltoid, biceps, brachialis anticus, and supinators. Paralysis of this group Erb attributes to a lesion of the sixth cervical, though Ferrier and Yeo deduce from their experiments that the fifth is also involved.

This group of muscles was in this case affected only to paresis, and it was evident that the chief lesion was below this point, as the intrinsic muscles of the forearm, wrist and hand were absolutely paralysed.

A destructive lesion or severe pressure upon the region of the seventh and eighth cervical would cause paralysis of the extensors and flexors of the wrist, while, if the region of the first dorsal was also implicated, the interossei and other intrinsic muscles of the hand would be likewise involved. This is exactly the phenomena.

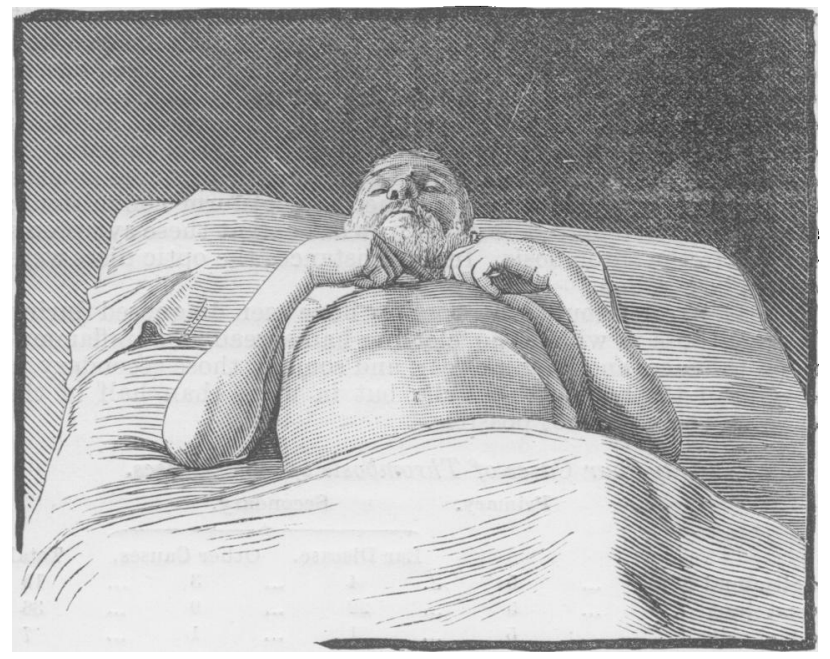

exhibited in this case, the chief force of the injury had expended itself on the region of the seventh and eighth cervical and first dorsal.

The sensory phenomena supported the deduction drawn from the motor. A lesion affecting all the brachial plexus below the fifth cervical would cause anæsthesia of the upper limb, except on the outer side of the arm and forearm and the radial border of the thumb, part of the region supplied by the musculo-spiral nerve. In this case the defect in sensation was most pronounced over the ulnar border of the arm and hand, while in the little finger sensation was in abeyance. This would again point to the eighth cervical and first dorsal, as they supply the little finger and the ulnar border of the arm and forearm.

It was also interesting to observe that the legs were free, while the intercostals were involved, though not by a destructive lesion, as they ultimately recovered their function.

The lesion was one which principally affected the anterior direct columns, and did not implicate the lateral crossed columns. It could have been produced by injury of the anterior part of the cord against the bodies of the vertebræ or the intervertebral discs, or probably by a hæmatomyelia. The region where hæmatomyelia most frequently occurs is that of the fourth, fifth, and "sixth cervical vertebræ. Here it was a little lower, the seventh cervical and first dorsal missing the fourth cervical. When hæmatomyelis 
is present it tends to affect the anterior cornua and the central canal. The case was looked on as one which probably was a bruising of the cord from over-extension of the cervical vertebræ, accompanied by hæmatomyelia. A crush at this region from displaced vertebræ would, in all likelihood, have resulted in more general spinal involvement, such as paralysis of the nerves of lower limbs.

Then, again, the lesion was unequal on the two sides, as the paralysis of the right arm was more severe than the other, while it was clear that the lesion on the right side was likewise destructive, as atrophic paralysis is now marked in the right hand and arm. It is possible that the last two cervical and the first dorsal

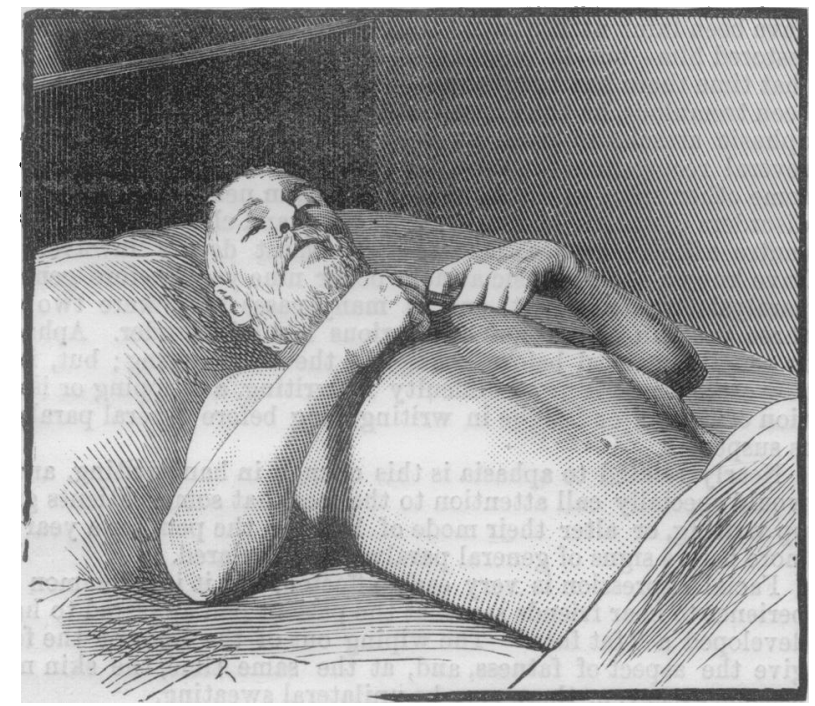

nerves may have had their roots specially injured, though both sides were here implicated at the same level, though not to same extent. The posture, as in the photographs, is typical of cord lesion about this region.

Trephining was not resorted to, as the diagnosis was that of over-stretching of the cord with consequent bruising and hæmatomyelia. There was no reason for trephining -no bone to elevateand the blood was probably very diffuse and involving the central canal. In the cervical region, especially in the vicinity of the fifth and sixth cervical centres, one would not be disposed to expose the cord unless for very obvious reasons, especially when the intercostals are paralysed, as slight ascending myelitis might paralyse the phrenic and lead to death. Regarding the diagnosis, a difficulty presents itself in explaining why the lower limbs escape from motor paralyses when the intercostals are paralysed. If one accepts the view that the anterior or direct tracts are chiefly related to the innervation of the arms, then an explanation may be forthcoming. From sections made at various levels of the cord, it is seen that the anterior pyramidal tracts lessen from above downwards, so that under ordinary circumstances, when the bulk of these tracts are about their usual size, they disappear near the middle of the dorsal region; when they are small in the upper cervical region, they may disappear about the middle or more probably about the end of the cervical enlargement; and when very bulky in the upper cervical, they may continue down to the lumbar enlargement. The innervation of the arm is located almost exclusively in the npposite hemisphere of the brain. These socalled direct tracts decussate, not in the medulla, but in the cord itself, probably passing through the anterior commissure to the grey matter on the opposite side. On the other hand, the lateral tracts, however small they may be in the upper part of the cervical, always continue down to the lumbar, enlargement. Were we accepting this probable explanation, believing that the anterior tracts (which are crossed in the cord) contribute mainly to the innervation of the arms, then we might further ask whether the intersostals are not also innervated from the anterior tracts? Were this answered affirmatively, the peculiarity noticed here (and this case is by no means unique in respect of the intercostals being implicated without involvement of the lower limbs, the leteral tracts not being involved in the lesion) would be ex- plained. This theory gains anatomical colouring from the fact that the direct tracts generally continue down the cord to the middle of the dorsal region, where the anterior tracts would terminate did they supply the principal respiratory intercostals.

\section{THE WARNINGS OF GENERAL PARALYSIS OF THE INSANE. 1}

By GEORGE H. SAVAGE, M.D.LoND., F.R.C.P., Lecturer on Mental Diseases at Guy's Hospital; late Senior Physician and Superintendent Bethlem Royal Hospital.

Gratleman,-I feel a great responsibility to-night in bringing before the meeting a subject so hackneyed as general paralysis, and yet if experience can justify my writing a paper, I have that plea at least. The gravity of the disease and its intractability make it intensely interesting, and as years pass on it seems to appeal to us more personally as one and another of our friends or patients fall out of rank, victims to this malady. I shall not go into the already well-described symptoms of the disease, but $I$ must premise by saying that it seems to me to be the disease of civilisation, and that the ratio of general paralysis is nearly the ratio of the high pressure life of cities. It is rare in the wilds and highlands of Great Britain and Ireland, and was rare in the negro of the Southern States, but the Highlander, the Welshman, and the Irishman die of the disease in cities, and with freedom the slave has acquired general paralysis.

It is further necessary to say that for the purposes of this paper I shall treat general paralysis as one disease, and one diseased process, though the symptoms may be manifold. I am more and more inclined to look at it as a degeneration, a premature decay, and as frequently having a local origin. I am in the habit of aaying that decay in a neglected house may fall on different lines according to the original structure of the house and to the surrounding causes of destruction; in the end, the four enclosing walls alone mey remain to mark the site of former human life, with its passions and its interests. So with the nervous edifice, the containing walls of organic life may for a time alone remain as witness of the past; yet we must remember that there is a considerable difference between the waste and decay produced by age and that resulting from the changes of general paralysis, and this will be noticed as we proceed to trace the earliest signs of the disorder.

It is always dangerous to be free in the use of metaphors, but I feel that I must use similes to make my meaning plain; already I have spoken of ruin and of decay, and I have said that this may have a local origin. It seems to me that just as a pear may remain long ripe and not decay, yet a bruise or a slight superficial injury will start the process of decay, so the overwrought brain may but need a local injury such as a blow or a local change in nutrition due to syphilitic or other vascular changes to set up the necessary process. "And so, from hour to hour we ripe and ripe, and then from hour to hour we rot and rot," and in considering the warnings of general paralysis, I think one must not forget the conditions under which the disease is most commonly met with. The botanist knows that he is likely to find his British orchids chiefly on chalky downs, and the physician expects to meet hisigeneral paralysis in the middle-aged men of good physique, and though certainly the orchid may be transplanted and live under other conditions, these are not its habitat, and so general paralysis may arise in other than its common surroundings. It is necessary to point out rather more in detail as we proceed the predisposing causes of general paralysis.

It must be fully recognised that extreme difficulty is often found in distinguishing between causes and early symptoms, for in many cases what may be causes of general paralysis also are often signs of the disease. Possibly drink, extravagance, restlessness, and sexual excess alone or combined may start the degeneration, but it is certain that one and all of these may be early signs of loss of the highest self-control. I shall, as far as I can, distinguish between these causes. And now for my field of work.

For several years while at Bethlem Royal Hospital, as soon as the friends of the patients fully recognised the hopelessness of the state of their general paralytic friends, I asked them to fill in a printed sheet, such as is before you, and with very little difficulty I obtained nearly a hundred such; in addition, I have put 